\title{
Human Parainfluenza Virus 2
}

National Cancer Institute

\section{Source}

National Cancer Institute. Human Parainfluenza Virus 2. NCI Thesaurus. Code C112316.

The serotype labeled 2 of the viral species Human parainfluenza virus, which is a singlestranded, negative-sense RNA virus of the Paramyxoviridae family and Rubulavirus genus, and causes croup and respiratory infections in humans. 